\title{
MÉTODOS MECÂNICOS E QUIMICO NO CONTROLE DE ERVAS DANINHAS EM CAFEZAL ( $\left.{ }^{(}\right)$
}

\author{
GASTÃO MORAES DA SILVEIRA $\left({ }^{2,5}\right)$, SERGIO AUGUSTO HIROAKI KURACHI $\left({ }^{3,5}\right)$ \\ e MAMOR FUJWARA $\left({ }^{4}\right)$
}

\begin{abstract}
RESUMO
O controle de ervas daninhas em cafezal cultivado em latossolo roxo, por meio de métodos mecânicos (grade de discos, enxada rotativa, roçadeira) e químico (herbicida), é comparado com a capina manual. Cada implemento foi sistematicamente usado durante o perfodo das águas. Quanto à produçāo, apos dez anos, não houve diferença estatística entre os tratamentos, a não ser no biênio 1976/77, quando a grade e a enxada rotativa tiveram melhor comportamento, não diferindo do herbicida. Observaram se sinais de erosto superficial provocada por grade de discos, enxada rotativa e herbicida.
\end{abstract}

Termos de indexação: mecanização agrícola, maquinaria agrícola, máquinas de cultivo, cultivo mecanizado, controle de ervas daninhas, cultura cafeeira.

( $\left.{ }^{1}\right)$ Recebido para publicaçăo em 26 de janeiro de 1984.

(2) Divisăo de Engenharia Agrícola, Instituto Agronômico (IAC), Caixa Postal 28, 13100 Campinas (SP).

$\left({ }_{4}^{3}\right)$ Seção de Projetos e Materiais, IAC.

$\left({ }^{4}\right)$ Seção de Café, IAC.

( ${ }^{5}$ ) Com bolsa de suplementação do CNPq. 


\section{INTRODUÇAO}

A competição das ervas daninhas em água, oxigênio e nutrientes é comum nas plantaçóes de café e, muitas vezes, o mato que permanece nos cafezais é responsável pelo amarelecimento das folhas e queda de produção.

O controle do mato mediante capina manual vem-se tornando uma operação onerosa devido à insuficiência e baixa qualidade da mão-de-obra existente no campo. Por outro lado, a capina manual é uma das atividades que mais demandam braço operário na cultura. De acordo com o INSTITUTO BRASILEIRO DO CAFÉ (1969), no sexto ano de um cafezal, a capina manual exige 9 homens/dia por mil pés, sendo ultrapassada somente pela colheita, que necessita de 30 homens/dia por mil pés. Em tal conjuntura, o uso de máquinas constitui alternativa viável para o médio e para o grande produtor de café.

No presente trabalho, estudam-se alguns métodos de controle das ervas daninhas, com ênfase à mecanização. $O$ cultivo feito pelo uso sistemático de grade de discos, enxada rotativa, roçadeira e herbicida, foi comparado à tradicional capina manual, dando prosseguimento ao trabalho desenvolvido por SILVEIRA et alii (1977/1978).

\section{MATERIAL E MÉTODOS}

O experimento, instalado em outubro de 1973, em latossolo roxo, na Fazenda "Santa Elisa", município de Analândia (SP), em terreno com cerca de $8 \%$ de declividade, no espaçamento de $4,0 \times 2,8 \mathrm{~m}$, com duas plantas por cova, utilizou cafeeiros do cultivar Mundo Novo com 3,5 anos de idade para formação de cafezal.

Foram realizadas as pulverizaçסes para o controle da "ferrugem", empregando-se oxicloreto de cobre a $50 \%$ na dosagem de $4,0 \mathrm{~kg}$ do produto comercial por mil covas, e, esporadicamiente, os micronutrientes zinco e boro, devido às deficiências encontradas na lavoura: o sulfato de zinco a $4,0 \mathrm{~kg}$ e, o ácido bórico, a $2,0 \mathrm{~kg}$ por mil covas. Os tratamentos foram efetuados com equipamentos acoplados a trator, com volume de 300 litros de calda por mil covas. De modo geral, como adubaçăo, usou-se a fórmula NPK 20-5-20, 1,2kg por cova, distribuída em quatro doses. Algumas vezes, a análise do solo indicou a necessidade de mudança na proporção dos elementos que compõem a formula, bem como na quantidade por aplicação.

Dos equipamentos utilizados no controle das ervas daninhas - grade de discos, roçadeira, aplicador de herbicida e enxada rotativa - os três primeiros foram descritos em SILVEIRA et alii (1983). 
A altura média da roçadeira nas várias aplicaçðes foi $0,06 \mathrm{~m}$.

Quanto à enxada rotativa, que apresenta rotação fixa das facas, utilizou-se um modelo com $0,97 \mathrm{~m}$ de largura de corte, com cinco flanges, tendo nas duas laterais três facas e, nas centrais, seis. Os resultados obtidos com tais implementos são comparados com aqueles da capina manual, na produção de café beneficiado.

Observou-se o número de capinas necessárias no decorrer de um ano agrícola, bem como o tempo decorrido entre capinas, para cada tipo de implemento. A capacidade de trabalho foi calculada determinando-se a velocidade e a largura de operação dos implementos. A fim de melhor caracterizar a qualidade do trabalho, foram determinadas as profundidades de operação.

O delineamento experimental foi blocos ao acaso, com cinco tratamentos e seis repetiçoes. Cada parcela era composta de uma linha de café com 48 plantas, trabalhando o implemento nas duas ruas adjacentes a cada linha. Desse modo, entre duas linhas consecutivas, há uma de bordadura, cultivada de cada um dos lados, com implementos diferentes. Os tratamentos foram aplicados somente nas ruas. Nas linhas, entre plantas, o cultivo foi feito sempre com enxada manual.

$O$ controle da produção foi realizado nas vinte plantas centrais de cada linha, e expresso em quilogramas de café beneficiado.

\section{RESULTADOS E DISCUSSÃO}

As modificações estruturais sofridas pelo solo, com o emprego de diferentes métodos de culïvo e seus efeitos sobre o comportamento das plantas, assim como os efeitos da compactação, foram avaliados em SILVEIRA et alii (1978).

No quadro 1 , são apresentados os dados de produção média relativa dos diversos tratamentos.

A análise de variância dos dados dos biênios (1974-75, 1978-79, 1980-81 e 1982-83) revela que estatisticamente não houve diferença entre os tratamentos, o que so ocorreu no biênio 1976-77, onde os tratamentos diferiram estatisticamente a $1 \%$. A grade e a enxada rotativa foram os tratamentos com melhor atuação, não diferindo estatisticamente daquele com herbicida. A capina manual e a roçadeira tiveram comportamento inferior.

Os resultados do biênio 1976-77 foram sensivelmente afetados pela geada de julho de 1975 e pela seca prolongada que se seguiu. O café do experimento sofreu bastante, embora não fosse preciso fazer a recepa. Nos biênios seguintes, a situação se normalizou, não se notando diferença entre os tratamentos. 
QUADRO 1 - Médias de produçăo de café beneficiado de vinte plantas, relativas aos diferentes tratamentos e biênios estudados

\begin{tabular}{lccccc}
\hline \multirow{2}{*}{ Tratamentos } & \multicolumn{5}{c}{ Biênios } \\
\cline { 2 - 6 } & $1974-75$ & $1976-77$ & $1978-79$ & $1980-81$ & $1982-83$ \\
& & & & & \\
\cline { 2 - 6 } & & & & & \\
\cline { 2 - 6 } & & & & & \\
Testemunha (capina manual) & 43,69 & $10,59 \mathrm{~b}$ & 65,49 & 78,95 & 67,11 \\
Herbicida & 39,82 & $17,52 \mathrm{ab}$ & 51,84 & 79,88 & 60,41 \\
Roçadeira & 34,27 & $9,95 \mathrm{~b}$ & 51,00 & 69,04 & 43,17 \\
Grade de discos & 39,94 & $26,66 \mathrm{a}$ & 64,75 & 76,62 & 44,12 \\
Enxada rotativa & 41,01 & $20,35 \mathrm{a}$ & 53,96 & 71,72 & 51,38 \\
\hline C.V.(\%) & 16,1 & 32,5 & 29,4 & 13,8 & 27,9 \\
\hline
\end{tabular}

Médias de tratamentos seguidas da mesma letra nao diferem significativamente entre si ao nivel de $5 \%$.

O quadro 2 contém os dados comparativos dos vários tratamentos utilizados. Apesar de, na maioria dos anos, não ter havido diferença estatisticamente significativa entre os tratamentos quanto à produção, observou-se em vários pontos da lavoura a formação de "degraus" entre a linha de plantas e a faixa onde passaram a grade de discos e a enxada rotativa, devido à erosão conseqüente a seu emprego. Esse fato, já observado por SILVEIRA et alii (1978), acentuou-se mais nos últimos seis anos. No caso de emprego de herbicida, embora em menor escala, notaram-se também sinais de pequena erosão superficial, devido à falta de vegetação para cobertura.

Quan to ao desempenho dos implementos e sua influência na produção, de acordo com PEREIRA \& JONES (1954) e JONES \& WALLIS (1963), era de esperar que a roçadeira, pela presença de mato no meio das ruas do cafezal, exercesse uma influência negativa na produção. Isso não aconteceu, pois foi tomado o cuidado de não deixar mato no meio da rua durante a seca. Para tal, antes do início desse período, o mato foi eliminado com a aplicação de herbicida. Assim, evitou-se a concorrência do mato com o cafeeiro pela água durante o inverno.

Outro ponto a destacar e que pode ser observado no quadro 2 , foi a economia de mão-de-obra obtida com a mecanização do controle das ervas daninhas. Quanto à capina entre as plantas na linha, a roçadeira deslocada exigiu menor quantidade de mão-de-obra. 
QUADRO 2 - Dados relativos ao desempenho de implementos e tratamentos utilizados no controle de ervas daninhas em cafezal em latossolo roxo de Analândia (SP) em $1974 / 83$

\begin{tabular}{|c|c|c|c|c|c|}
\hline \multirow{2}{*}{ Tratamentos } & \multirow{2}{*}{ Aplicaçðes } & \multicolumn{2}{|c|}{ Capacidade de trabalho } & \multirow{2}{*}{$\begin{array}{l}\text { Profundi- } \\
\text { dade de } \\
\text { trabalho }\end{array}$} & \multirow{2}{*}{$\begin{array}{c}\text { Largura } \\
\text { de } \\
\text { trabalho }\end{array}$} \\
\hline & & Nas ruas & $\begin{array}{l}\text { Entre } \\
\text { plantas }\end{array}$ & & \\
\hline & $\mathrm{N}^{0}$ & \multicolumn{2}{|c|}{$\begin{array}{l}\text { Homens/hora/ } \\
/ 1.000 \text { covas }\end{array}$} & $\mathrm{m}$ & $\mathrm{m}$ \\
\hline Capina manual & 37 & \multicolumn{2}{|c|}{$85\left(^{*}\right)$} & - & - \\
\hline Herbicida & 38 & 0,7 & 30 & - & 3,20 \\
\hline Roçadeira & 46 & 1,6 & 25 & - & 1,20 \\
\hline Herbicida antes da seca & 9 & 0,7 & 30 & - & 3,20 \\
\hline Grade de discos & 48 & 1,0 & 30 & 0,07 & 1,30 \\
\hline Enxada rotativa & 44 & 1,5 & 30 & 0,07 & 0,95 \\
\hline
\end{tabular}

(*) Na capina manual, o dado engloba o controle de ervas daninhas executado nas ruas e entre plantas.

No presente trabalho, os vários implementos foram usados sistematicamente, o que ocasionou o aparecimento de problemas de erosão superficial na grade, rotativa e herbicida. Isso pode ser evitado utilizando-se os implementos alternadamente segundo SILVEIRA et alii (1983), que empregaram as seguintes combinaçðes: enxada rotativa e herbicida; roçadeira e enxada rotativa; roçadeira e grade; e roçadeira nas águas e herbicida durante a seca, comparadas com a testemunha (capina manual), não havendo, também, diferença estatística entre as várias combinaçôes, quando analisada a produção.

\section{CONCLUSOES}

a) Quanto à produção, exceto no biênio 1976-77, não houve diferença entre os tratamentos utilizados, isto é, capina manual, herbicida, roçadeira, grade de discos e enxada rotativa.

b) Embora a economia de mão-de-obra fosse maior quando se empregaram métodos mecânicos e químico, a grade de discos e a enxada rotativa, em maior intensidade, e o herbicida, em menor, causaram problemas de erosão superficial do solo, formando degraus nas entrelinhas. 


\section{SUMMARY \\ MECHANICAL AND CHEMICAL METHODS OF WEED CONTROL IN COFFE CROP}

Mechanical (disc-harrow, rotary cultivator, off-set rotary shredder), chemical (herbicide) and hand hoe weeding are compared in a coffee crop grown on a latosol. After ten years there was no significant yield difference among the treatments. There was however, visible signs of erosion due to the use of disc-harrow, rotary cultivator, and herbicide.

Index terms: agricultural mechanization, agricultural machinery, tillage machine, mechanical tillage, weed control, coffee crop.

\section{AGRADECIMENTOS}

Os autores agradecem à família do saudoso Dr. Domingos Farano a cessão do cafezal e facilidades oferecidas na condução dos trabalhos.

\section{REFERENCIAS BIBLIOGRAFICAS}

INSTITUTO BRASILEIRO DO CAFÉ. Racionalização da cafeicultura brasileira. Rio de Janeiro, IBC-GERCA, 1969. 115p.

JONES, P.A. \& WALLIS, J.A.M. A tillage study in Kenya coffee. Part. III. Empire J ournal of Experimental Agriculture, 31:243, 1963.

PEREIRA, H.C \& JONES, P.A. A tillage study in Kenya coffee. Part. II. Empire Journal of Experimental Agriculture, 22:232, 1954.

SILVEIRA, G.M.; GROHMANN, F.; KURACHI, S.A.H. \& FUJIWARA, M. Influência do sistema de cultivo na estrutura do solo em cafezal. O Agronômico, Campinas, 29/30: 149-157, 1977/1978.

; KURACHI, S.A.H. \& FUJIWARA, M. Comparação de métodos mecânicos e químicos no controle de ervas daninhas em cafezal. O Agronômico, Campinas, 29/30: 137-148, 1977/1978.

mecânicos e químicos de controle de ervas daninhas em cafezal. Bragantia, Campinas, 42:37-46, 1983. 